\title{
10 The struggle to belong: Trans and gender-diverse experiences in Japan and Norway
}

\author{
france rose hartline and Keiichiro Ishimaru
}

\section{Tracing the boundaries of gendered belonging}

Movements across the world advocating for the rights of transgender and gender-nonconforming ('trans') people have wrought immense cultural changes. These have occurred in tandem with an upsurge in trans political visibility and a growing push for gender diverse inclusion and recognition. The results have varied from context to context, materialising through new policies, practices and ideologies as well as bouts of governmental ambivalence and societal backlash. Two countries - Norway and Japan - present productive case studies for comparison given their divergent responses to trans rights advocacy. Norway has recently enacted numerous laws in response to the push for trans equality, while in Japan trans activists have met repeated resistance, making for slow progress. Though this would appear to give an irrefutable indication of how diversity issues are regarded in each country - with Norway demonstrating its reputed exceptionalism for human rights and Japan lagging far behind - we believe the actual situation is far more complex and deserving of a critical review. Indeed, our study reveals considerable convergence of the two contexts on the issues of sterilisation, gender recognition and trans belonging.

In this chapter, we reflect on the framework of the law/medicine/society triad in order to explore what trans rights means for gender diverse individuals in each country. We focus on how legal recognition of gender, or the lack of such, has intersected with the medical and social realms to shape gendered experiences of belonging. To do so, we draw on personal interview narratives collected from trans-identifying activists in Japan and Norway. These stories allow us to better understand how and to what extent gender diversity materialises and becomes viable within each sociocultural context. This comparison enables us to trace the boundaries of gendered belonging as they are formulated within each context.

We begin with a brief description of gender diversity and modern trans rights development in each country. Then, we outline the theoretical framework, method and methodology we have applied in our collection and analysis of the interviews. Finally, we present a discussion of the interview data from Norway and Japan. 


\section{Background: Setting the stage}

In both the Norwegian and Japanese contexts, three sites of tension emerged repeatedly in the interviews when discussing experiences and interpretations of trans rights - namely, the triad of society, medicine and law. Trans people's narratives of struggle uniformly invoke the power held by these three intersecting realms. The triad draws on the discourse surrounding Western interpretations of rights and empowerment, which forms the foundation of the globalising movement for transgender and gender diverse (trans) equality. This framework defines equality within society as based on recognition and respect for one's experienced gender identity as well as a sense of belonging, security and futurity. Law refers to the state or region's sanctioning of procedures, laws or practices that benefit and protect trans people. In the realm of medicine, trans rights can be characterised by unfettered, well-supported access to gender-affirming medical technologies and practices.

Interpreted loosely, this triad model can effectively be applied across the globalising trans rights movement, no matter the context. The movement's emergence coincided with the materialisation of trans-ness as a politically-, medically- and socially-indexed positionality. Cultural differences within and across national boundaries, however, also shape trans lives, embodiments and experiences. They do so in ways that do not always (or often) coincide with how trans rights and equality - or trans oppression and inequality - appear according to the Euro-Americo-centric model from which the trans movement has emerged. This calls for attending situationally and proportionally to the triad's power when making cross-cultural comparisons. In particular, this chapter considers the difference between Norway and Japan concerning the sterilisation requirement for legal gender change, and the resultant impact on experiences of societal belonging. Passing legislation to overturn this requirement has been central to trans activists' efforts around the globe over the past two decades, with varying results. With this in mind, the following gives an overview of how gender diversity has materialised and been institutionally formulated within each country since the late 20 th century.

\section{Norway}

Like its Scandinavian neighbours, Norway began implementing transspecific practices and policies relatively early from a modern perspective. The roots of gender diversity in Norway are largely traceable through medicine and law. Medical treatment for 'transsexualism' (the diagnostic term) became available in the 1960s through sex reassignment surgery. In the 1970s, this practice was formalised into an administrative procedure, whereby complete sterilisation would make one eligible for legal gender change. Though never codified in law, the sterilisation requirement for 
changing one's juridical gender would remain in place for decades until pressure from international and local human rights organisations tipped the scales. In 2016, Norway's Gender Recognition Act (GRA) took effect, following in the wake of the Sexual Orientation Anti-Discrimination Act 2013, which protects people from discrimination on the basis of gender identity and expression. Norway's GRA proved to be one of the most progressive of its kind. Based on the self-determination model, it allows one to choose to change gender without any medical intervention. No diagnosis or medical treatment is required; one need only to be a resident or citizen, and at least 16 years of age (or six years, with guardian consent) to request a change marker gender. Moreover, one could change back and forth infinitely, and there is no waiting period before the change takes effect. Once one has changed legal gender, they receive a confirmation of this change (which many call their 'papers' or 'letter'), and this can be used to change all personal identification documents.

The GRA stands out amongst the slew of acts which have speckled the world over the previous two decades. Most countries' versions of GRA require that one first receive a diagnosis of transsexualism or gender identity disorder (e.g., Sweden and Finland), will remain in their new gender (e.g., UK) and is of adult age (nearly all countries which have a GRA); some also require that one observe a 'reflection' period (e.g., Denmark). However, despite its remarkable qualities, trans advocates are quick to point out several shortcomings of Norway's 2016 GRA. To begin, one cannot choose a third gender or to opt out of the gender designation system entirely. Another shortcoming is that there has been no concurrent improvement in trans-specific healthcare, which continues to be monopolised by the state. The lack of second opinions or private options, combined with normatively exclusionary selection practices, has precluded a significant proportion of trans people from accessing the healthcare they need (Sørlie, 2015, 2018; Van der Ros, 2017).

\section{Japan}

While Japan has a long history of gender malleability (McLelland 2007; Suganuma, 2012), juridico-medical and societal attention to trans rights is relatively recent. The 1990s witnessed an LGBT 'boom' in Japan, during which queer activism and visibility grew exponentially for several key reasons - namely, the spread of internet access, the advent of HIV/AIDS activism (and the resultant spotlight on male same-sex sexual practices) and the destabilisation of hegemonic masculinity following the country's economic downturn (Robertson, 2017). In this period, trans issues took hold as activists began pushing for a place to belong outside of the entertainment and service industry. However, in line with the broader LGBT movement, trans activists' demands were deeply entrenched in Western cultural values. As a result, Japan's response was, and still is, reticent - though not as 
reticent as toward gay and lesbian rights demands. As in many non-Western contexts, trans people in Japan have made the most progress of the LGBT cohort. Gay and lesbian people have been seen as defiantly disrupting society by choice, whereas trans people - due to being ensconced in the medical system - have been seen as disabled people in need of treatment for rehabilitation into society. Thus, Japan began allowing sex reassignment surgery in the late 1990s, after which it followed the emerging Western trend in 2003 by passing a law which allows one to change legal gender in the family register (koseki) following irreversible sterilisation. This law, called Gender Identity Disorder Special Cases Act ([GID law], 2003), ${ }^{1}$ was regarded as quite progressive at that time by the LGBT community at large. Patients who have received the Gender Identity Diagnosis (GID) but have yet to be sterilised and change legal gender are provided a GID certificate as a stopgap by psychiatrists. This certificate confirms their diagnostic status, thereby making it possible to both change legal name and $\left(\right.$ ostensibly $\left.{ }^{2}\right)$ be better protected in various social situations, such as public restrooms. Moreover, in early 2018, the government began financially supporting those who choose to undergo medical transition by covering $70 \%$ of the surgical costs, though this is is precluded by any hormonal treatment prior to surgery. While governmental support in gender-confirming medical practices is undoubtedly positive, the trans people we spoke to describe a situation similar to that in Norway - namely, that the health practitioners prioritise the needs of those who present more gender and sexual normative narratives, lending to a high rate of exclusion.

The trans community has seen little legislative progress since 2003, as there continue to be no national provisions to protect individuals on the basis of gender identity or sexual orientation. Furthermore, despite a mounting pressure from human rights groups that culminated in a lawsuit challenging the sterilisation requirement in 2019, Japan's government has upheld the constitutionality of its GID law (Human Rights Watch [HRW], 2019). Promises to improve LGBT people's lives have seldom come to fruition. However, Japan's position as the 2020 Olympics host as well as the only G7 country to maintain its restrictive practices suggest that there may be changes afoot.

In the meantime, many trans people continue to live in stealth or with gendered appearances contrary to their legal identification. Societal awareness is limited, as representations of trans diversity outside of pathology are largely confined to the entertainment and service industry (McLelland, Suganuma, \& Welker, 2007), and thus do not allow much space for seeing trans as a deeper, overarching experience and embodiment. More and more advocacy organisations are being established to promote societal awareness and support trans people. General awareness around LGBT issues is undoubtedly growing but due to the lack of legislation protecting queer and trans people, as well as a cultural pressure to blend in, many trans people continue to feel disadvantaged and misrecognised. 


\section{Theoretical foundation}

This chapter applies a transfeminist framework of interpretation, which facilitates a critical gaze toward gender by dissecting non-normatively gendered experiences, embodiments, identities and desires. The 'feminism' of transfeminism contributes with a heightened focus on the intersectionality of compounding oppressions in shaping gendered subjectivities. Together they lay the groundwork for investigating the dynamic topography of genders and what possibilities for identification are opened and closed by existing social, legal and medical structures (hartline, 2020a, p. 73; Stryker \& Bettcher, 2016, p. 8). Transfeminism's approach to gender is special in that it avoids dividing the scope into cisgender and transgender, rather seeing gender as a valuational system that implicates all people to varying degrees across varying situations.

Gender, sex, identity and power have specific meanings in specific contexts at specific times, and part of a transfeminist approach is avoiding cultural imperialism by maintaining contextualisation (Connell, 2007; Sprague, 2016). The LGBT rights movement as Euro-American-oriented ushers in particular notions of what it means to be visible and empowered (Tudor, 2017). Formulating contextually relevant approaches to understanding LGBT experiences amidst the geopolitical shifts of globalisation is gaining momentum as a practice in many non-Western contexts by feminist and queer scholars (Massad, 2002; Suganuma, 2012). These approaches examine how diverse sex/sexual/gender identities, desires and behaviours are made viable (Connell, 2007).

From the macro-level, we apply the theoretical tool of the (cis)gender imaginary, which unearths the ways in which gendered possibilities are shaped by a particular sociocultural context (hartline, 2020a, 2020b). The (cis)gender imaginary is the space in which gendered norms are (re)produced and embodiments materialise or deteriorate. It distinguishes the viable from the monstrous, the desirable from the abject. (Cis)genderism remains the status quo even amidst ostensible efforts to undo it. Engaging with this concept points us away from focussing largely or exclusively on legislation and institutionally sanctioned practices, and toward the intricate weavings of the sociocultural fabric. Thus, it becomes feasible to understand how gendered experiences are shaped through affective modes of living and belonging, enabling a more balanced comparison between two differing national contexts.

From the micro-level, the research project is theoretically framed by the concept of 'belonging,' which describes the affective conditions of recognition, stability and participation (Aultman, 2018; Probyn, 1996) and the 'cognitive and emotional dimensions of identification and attachment' (Yuval-Davis, 2009, p. 4). Contrary to 'identity,' which implies a stable self, or 'citizenship,' which marks only the formal boundaries of membership, 'belonging' illustrates how the self metamorphoses in tandem with its 
environment by articulating the 'material cultural locality' that shapes the individual's subjectivity (Probyn, 1996, p. 5). As an analytical tool, it enables an examination of the individualised and communal projects that trans people undertake in responding to marginalisation.

\section{Method and methodology}

This chapter draws on interviews conducted with self-identifying activists in trans communities in Norway and Japan. In Norway, 15 individuals were interviewed: 12 of whom had changed legal gender following the enactment of the GRA in 2016, and three of whom who chose not to do so. These were single, one-on-one interviews, directed toward understanding how the individuals came to a decision about legal gender change and the impact of the decision on their lives. In Japan, 11 individuals were interviewed; this included seven individual interviews and one group interview with four people. Also, once-off, these interviews were aimed at understanding how the individuals experienced being trans or gender-diverse in Japan amidst a lack of protection and non-sterilisation-based recognition, including how they came to a decision about sterilisation and legal gender change. Both sets of interviews aimed to collect individual experiences of gender diversity and reflections on trans rights. The interviews in Norway and three of the interviews in Japan were conducted alone by co-author hartline; the remaining eight interviews in Japan were conducted together by the two authors, hartline and Ishimaru. In all cases, the services of a queeridentifying interpreter was on offer; in Norway, everyone chose to speak in English with hartline; in Japan, half the participants spoke in English and the other half in Japanese with the aid of either co-author Ishimaru or a hired interpreter. All interviews were transcribed in English by hartline.

The decision to focus on activist accounts was initially incidental. As an unintended consequence of the snowballing method as well as the tendency for interested interview subjects to be 'out' and active in the community, the vast majority of the interviewees in each context were trans activists and open about their identities in everyday life. Therefore, the representative quality of the data is limited in terms of what trans lives are generally like, since those who are openly trans are likely to have a markedly different interpretation and awareness of societal attitudes than those who are stealth or not yet out to themselves. We have chosen to take advantage of this skew in the data by drawing on the interviews as not just stories of personal experience but also as grounded insights into how institutions understand and help shape gender diversity. Having an activist background is valuable for becoming attuned to discourses around gender, as well as making one keenly aware of gender practices in general. With this distinction in mind, however, we also maintain vigilance when generalising activists' stories; there is a certain amount of social capital accumulated by being out and well-connected with others in the trans community, as well as cultural 
capital in having access to more diverse knowledge around trans rights within and beyond the national context. We therefore contextualise the selected quotes in order to give depth to each participant's perspective.

\section{Discussion}

Our point of departure in exploring the narratives is the experience of legal gender change, as trans-specific legislation is the biggest difference between Norway and Japan when it comes to trans rights. As described in the Background section, Norway began allowing for legal gender change without sterilisation or diagnosis in 2016, whilst in 2019 Japan upheld the constitutionality of its GID law, 2003, which requires irreversible sterilisation for legal gender change. In both Norway and Japan, the experience of legal gender change highlights the character and power of the state. Norway's history of social democracy and welfarism and Japan's hierarchical structure and deference to authority, both lend the state and its institutions a particular credence regarding the legitimacy of gender expressions, embodiments and identities. The following discussions draw on the interview data to focus on how legal recognition of gender, or the lack of such, has intersected with the medical and social realms to shape gendered experiences of belonging. Participants' reflections on three key issues guide the discussion: 1. Attitudes toward sterilisation (as a transitioning practice and as a social and/or legal requirement); 2. Gender-diverse un/ acceptance across institutions; 3 . Achieving a sense of belonging as a trans person. To provide context to the quotes, each participant's stated gender identity, age range and legal gender are provided (in this order).

\section{Attitudes toward sterilisation}

\section{Norway}

None of the Norwegian participants had undergone sterilisation at the time of the interview, and most described it as unnecessary, even counterproductive, for their own transition journeys. Several felt frustrated that the state waited so long to make legal gender change possible without sterilisation. Lene (non-binary, 30s, F) asked, somewhat rhetorically, "Why wasn't this [option] available sooner? Why do we need to bureaucratise people's bodies? Pathologize bodies?' Anders (transman, 20s, M) shared this sentiment, adding that he was glad he could now avoid sterilisation. He had believed in the past that it was right for him, but eventually he realised that it was not that he was 'born in the wrong body,' but rather that society simply did not 'understand [his] body.' 'Being male,' he explained, 'doesn't necessarily mean cis male, with a flat chest, penis, beard, muscles, etc.' Becoming legally male without sterilisation, for Anders, had 'given back sovereignty over [his own] body.' 
Some of the Norwegian participants were still pursuing sterilisation despite the GRA's enactment. Ana (woman born in the wrong body, 30s, F) shared that while she felt more confident with her new legal gender, she did not feel free to behave exclusively like a woman because she had not yet completed her gender-affirming medical treatments. As an example, she explained that she still would not shower with other women at the gym, even though she could, if needed, justify her presence with documentation of her legal gender change. Her concern was about not imposing on people around her:

I don't know, maybe for others it's different, but there are some things I feel that you can't do if you still don't have the right body. Not only because you can't, but you shouldn't. You shouldn't be rude to other people, you should respect them. (...) Having the papers [confirmation of legal gender change] is not enough.

This perspective was shared by Bente (transgender woman, 60s, F). While finally getting her female identification had been a 'victory' and helped her be more authentic with herself and others, she still felt incomplete due to having been denied trans-specific healthcare. She explained that every time she undresses in front of the mirror, she would see someone who was 'a transgender, not yet a real woman.' For both Ana and Bente, genderaffirming treatment via sterilisation was a critical part of their transition, and legal recognition could not compensate for the lack of physical shift.

\section{Japan}

Attitudes amongst the Japanese interview participants are quite negative toward sterilisation. This is not surprising given their activist status, but this stood in stark contrast to the Norwegian collective. The fact that sterilisation was still a requirement for legal gender change, rather than simply an option for one's transition process, likely made it feel more oppressive to them. Discussions on undergoing sterilisation arose only in relation to the need for security, particularly regarding employment. Mariyo (woman, 30s, M) said that although she did not want to, she may have to undergo sterilisation in order to procure a stable job: 'Being unemployed, I feel excluded from society, and I think it requires a legal gender change to change that.' Yukihiko (man, 30s, M) had chosen to be sterilised in young adulthood in order to secure employment, but it was now a decision he felt he should not have made:

I didn't really want to remove my ovaries, because I'd never seen them, they're not visible. But it was really difficult for me to start working as a man with the female marker, so I had the surgery. At that time, I didn't think it was a big deal. I thought, 'Well, as long as I change my legal 
gender, a lot of things will solve itself.' But that was not so. (...) It took away my ability to produce children. (...) Now, if I met a man that I love, then maybe I would have had a child. And now I can't get legally married, unless the law changes, because I'm gay and men can't marry. So, it's a bit like, 'Well, what did I do this for?'

Several other participants had chosen to avoid changing their bodies, not just to preserve function but also integrity. Uzuki (woman, 40s, M) had always opposed the GID law, saying that it unduly pathologizes transgenderism as a disability and thus compels people to change their bodies for society:

Getting operated on and getting surgery is a very personal issue for me. Surgery is not a social issue. You don't have to have surgery to be socially accepted. (...) I don't want to do it just because I am told to. (...) I want to be an example for others.

\section{Gender-diverse un/acceptance}

\section{Norway}

In reflecting on their experiences of acceptance, the Norwegian participants' stories varied widely. Some felt generally empowered in Norway, particularly following the GRA's enactment. The protection afforded by the GRA was clear in nearly all the participants' narratives. Torill (woman/transperson, 60s, F) said that after changing legal gender, she no longer worried about passing: 'I'm not afraid at all anymore, I'm quite brave.' As an activist, she has felt more able to speak openly about being a 'woman living in a male body.' When people challenge or question her, she tells them, 'It doesn't matter that you don't understand, because it is not your problem. I am the only one who knows who I am.'

However, many felt that Norway continues to disregard many of trans people's needs, as exemplified by the binary requirement. Lene (non-binary, $30 \mathrm{~s}, \mathrm{~F})$ felt there was no space for her to be genuine, since society and the state validate only binary-identifying people. She had changed her marker from male to female to match her socially read appearance, but she still felt misplaced:

I don't appreciate having binary ideals forced onto me. (...) You can't actually live a good or happy or productive life under any of those circumstances where society or the system is pressuring you into something you're not feeling comfortable with....For the general view of society, the binary does not represent reality at all. 
Sebastian (transman/queer, 30s, F) shared this feeling, thus why he had not changed legal gender despite his masculine appearance:

I feel sort of like [changing legal gender] has become an obligation just because I pass as a man and it is an option now. How is that different from being told before what gender I had to be? (...) I'm worried that if I change my gender marker, then I'll just be another typical guy in the world, and my whole history of fighting for acceptance and coming to terms with myself and feeling pride will be erased in the eyes of society. I want to live as a transman, not just a man, but we have to choose one presumably cisgender category or the other.

Sebastian also noted his frustration with the ostensible progress that Norway has made for trans rights, imploring, 'Let's not pretend this is the final stop on the rail line toward trans equality. Far from it. The train has just barely started moving.'

Furthermore, many of the transwomen (though none of the transmen) in the Norwegian cohort expressed a continued fear to enter private spaces. They did not feel that having a legal gender marker would necessarily protect them against rejection by others, particularly in gender-segregated spaces. In line with Ana's above-quoted refusal to shower at the gym before completing her medical treatment, Bente (transgender woman, 60s, F) did not yet dare use women's public bathrooms. She always opted for the handicapped toilet, for fear of being scolded by those who presumably deserve to be there. To be rejected in such an intimate space by 'real women' would negate her femininity to an indelible degree. Lene (nonbinary, 30s, F) also worries about rejection due to her anatomy, describing the possibility of getting into 'gender trouble.' Even though she passes as a woman, the stress of being discovered as 'not truly female' proves too trying.

\section{Japan}

The struggle to have one's trans or gender-diverse identity validated through the state and society was also a recurring element in the Japanese participants' narratives. Several spoke of the 'façade' of acceptance in Japanese society, noting the disjuncture between appearance and reality. For example, Sayae (woman, 20s, M) explained that the lack of violence towards trans people does not indicate respect:

No one has ever said to me, 'I hate you, I don't like you.' Japanese people never say when they don't like someone, they don't say it directly. [People] only say good things. It's not good. (...) We are never killed, we are never raped. But it doesn't mean that we are happy. (...) We should speak up more, so people know. 
Jinya (man, 30s, F) expanded on this, highlighting the in-between status of trans people from a legal perspective - not quite prohibited but not quite allowed:

We LGBT people are not criminalised, so we don't get arrested in Japan, but when we have to depend on the government, we aren't recognised, so we can't really get the same support that other people do. And that means that we are second class citizens. So that's really hard for us. (...) I don't feel safe living in Japan.

Because gender identity disorder (GID) is regarded as an unfortunate, but curable, illness in Japan, the apparent respect for trans people is conditioned upon the trans person's intention and desire to undergo sterilisation. For those who do not undergo it, genuine acceptance is difficult to come by, not only in broader society but also with the trans community. There is a hierarchy of belonging that ranks those who identify as the medical term 'GID' above those who identify as the Western term 'trans.' Broadly put, the former seek to undergo sterilisation to become 'typically' sexed and pass within the binary, while the latter seek to challenge the binary by avoiding sterilisation. The divisiveness of the trans political landscape is of course not unique to Japan, but it may be amplified there due to limited knowledge on gender variance beyond small activist circles. The participants described the situation as improving, but still they worried that the sociolegal emphasis on passing was pressuring uninformed youth to pursue measures they may regret later, as captured for example in Yukihiko's story above. The limited representation of trans people proves problematic for those just beginning to explore their identities. When Keito (man, 30s, F) was young, he had thought undergoing complete transition was necessary for acceptance because there were no gendernonnormative role models to look to for alternatives. As an adult activist, he had learnt to be proud of his transness and now worked with others to promote alternative ways of transitioning. He explained why:

Japanese people think trans people are very poor and discriminated against and have poor health. Many people look down on trans people. They don't realise that trans people can be happy. (...) They discriminate against trans people who aren't normal, especially outside the big cities where there is no concept of diversity. (...) Trans people internalise this discrimination.... and think they must choose to be either a man or woman. (...) We need to show [people] that we can be happy without being normal. 


\section{Achieving a sense of belonging}

\section{Norway}

In their personal projects for securing a livable life, several of the Norwegian participants found that passing fully as a man or woman provided them with a sense of belonging since their internal self is validated through acceptance as legitimately situated within the gender binary. The new identity marker, for example, was a stamp of approval from the state that could be deployed in difficult social situations. Camilla (woman, 20s, F) had always identified as a woman despite not always passing, but with her new legal marker, she saw herself as 'real female, a born girl.' She now felt she could improve her life by demanding more respect from the state welfare system and her employer, both of which she believed had treated her poorly for being trans. Dolores (woman, 50s, F) also felt validated by legal gender change, but since she had been turned down for much-wanted medical treatment, she found herself figuring out how to live with male genitalia. She strove to take pride in her status as a 'woman with bollocks':

I like the double meaning of it. There's another way to see it. A woman with bollocks is standing and fighting for herself. She has got a mouth and she is there for herself and for her beliefs. She's not bad, but she can be brutal, standing up for her mates and her kids, forever.

After changing legal gender, Dolores had begun to feel more secure in herself, even returning to some of the masculine activities and clothing she had given up in trying to be accepted as a woman. She took pleasure in being able to forego femininity in her hobbies and expression but still be a 'real woman.'

For some of the Norwegian participants, however, there continued to be a disconnect between self and the society/state, despite progressive legislation and relatively low reports of trans-directed discrimination. It became particularly clear here how underlying cisgender norms were still shaping subjective experiences of the gendered self, delimiting possibilities for embodiment. Ingrid (transwoman, 30s, M) had decided against changing her legal gender from male to female because she did not feel she passed in everyday life. Having been turned down for trans-specific healthcare, she found herself lingering in a precarious position as she was unable to afford gender-affirming treatment on her own. Ingrid explained that changing legal gender could actually make her life more difficult, as she would lose the ability to resume a masculine role when safety and security were at stake, such as when travelling abroad or applying for jobs. She asked, 'What is the point of changing my legal gender if society still doesn't see me?' While becoming legally female may well compel institutional and social actors to openly regard her as a woman, Ingrid believed that it would 
not necessarily compel their respect. As demonstrated with the issue of intimate spaces discussed above, societal attitudes are not fully subject to the state's approval, so trans people must navigate public life carefully.

\section{Japan}

Most of the Japanese participants were actively engaged in LGBT organisations, which provided them with a space for (co)validation and the power to promote personal causes. Across the interviews, there was a tendency to eschew complete institutional involvement in their transition processes, preferring rather to remain radical to some degree. For instance, Naoto (man, 30s, F) spoke of his decision to not take testosterone, even though he would have enjoyed the physical changes and passing as a man. His partner was a ciswoman, so he worried that he would be read as a cis-heterosexual male. He thus preserved his queerness through this act of bodily defiance, by claiming a belonging to masculinity whilst rejecting its principle standards. Okito (man, 50s, F) shared a similar approach, citing his desire to live outside the binary - 'after 48 years inside it' - as a reason for not having pursued hormone treatment. He considered the medical transition process to be only one of many ways to grow into oneself, and he found meaning in being an example of this:

We think of trans as 'transing' - crossing - the boundary, but I like to think of it as 'transcending' gender. If I stay in this transcending state, and not choose one or the other, then maybe it will help other people do the same. People, all people, need to be more self-expressive and self-assured. Marriage, children, gender, hormones, operation - everything should be a choice, and not be enforced. (...) We need more freedom of spirit so we can choose.

Sayae (woman, 20s, M) also believed that the government was trying to be too involved in governing trans lives, but she was personally invested in passing socially. Having been on hormones for two years, she was appearing more feminine, which had made her life simpler:

I care about legal gender, but more than legal gender, I care about whether I look like a woman. That's what's important for friends and parents. So, if I look better, my parents stop caring, stop wanting to make me stop [being trans].

Sayae felt more accepted amongst her loved ones when she did not overly challenge their notions of gender identity. She did not feel further medical intervention is necessary for her, which she attributed to her privileged position. She was employed by an international company that allowed her to identify openly as a woman despite being legally male. Moreover, she 
was fluent in English and was involved in both local and international trans activism, which had vastly expanded her knowledge of gender diversity. Nonetheless, she did not feel comfortable enough to be openly trans beyond her work and home life. It was important for Sayae both fit in with society as well as to be a representative for diversity. As seen amongst the other Japanese participants, the degree to which each positionality was sought depended upon a mix of desire and ability.

\section{Conclusion}

In this chapter, we have explored the struggles faced by trans people in both Norway and Japan in order to highlight some of the commonalities and differences in how trans belonging is understood and experienced. We found that in both Norway and Japan, the individuals we interviewed generally expressed significant disappointment with the status quo of trans rights. There was a pervasive sense of non-belonging - nationally, socially, and, for most, psychically and physically. The maintenance of the cisgender standard, via the (cis)gender imaginary, became evident again and again through the internalisation of incompleteness or misrecognition by most of the participants. They spoke of their repeated encounters with uncrossable boundaries and the tension it caused with their senses of self. In reconciling the tension and carving spaces of belonging, some sought to find pride and purpose in these radical positionalities, whilst others strove to align themselves better with societal expectations in order to enhance their security and life quality. Several had occupied both ends of the spectrum during their transitions, drifting across due to circumstance and desire.

Initially, we had anticipated that the stories from our Japanese participants would demonstrate a greater degree of non-belonging than those of our Norwegian participants. However, the difference was curiously narrow, leading us to speculate that it may be in part due to culturally conditioned expectations surrounding institutional support. We suspect that the promise of the Norwegian state (both implicit and explicit) to protect its citizens through uniquely progressive legislation and practices, particularly regarding gender equality, has imprinted upon trans people's expectations of the state in such a way that any dissonance between one's felt reality and the national imagery of equality becomes amplified, leading to a sense of frustration - and even personalised failure (hartline, 2020a). Meanwhile, the traditions of gender segregation and inequality in Japan have long obliged trans people to find alternative modes of coping with misrecognition and limited protection; with little anticipation of state support for diversity, it has been necessary to claim livable spaces outside state-endorsed boundaries of inclusion. 
This difference was especially highlighted in how the two groups regarded the repeal of the sterilisation requirement. While in Norway the participants expressed the feeling of 'det skulle bare mangle' ('it is now as it should be') after the GRA's passing, many of our Japanese participants, despite being trans rights activists, were not even aware that the sterilisation requirement had been recently upheld as constitutional following a lost lawsuit in Japan's supreme court ('Japanese transgender man,' 2019). Putting aside the fact that a new act tends to make bigger waves than a lost lawsuit, it was clear that while the Norwegian participants strongly related their journeys to the state's involvement, many of the Japanese participants considered localised participation, community and employment security and small-scale redress to be more important for improving their situation. Relying on community (which one can help shape) over the state and its institutions can make belonging more achievable, which may explain why the Japanese participants did not seem to be struggling a great deal more than the ones in Norway. However, this is a benefit only so long as one has sufficient access to a like-minded community. This is why it is necessary to read the Japanese activists' narratives with a critical lens, as they are underwritten by a degree of privilege likely to be lacking from many, if not most, trans people's stories.

In this chapter, we have sought to provide insight into the limitations and experiences of trans people in Norway and Japan in order to demonstrate the nuanced contextuality of gender diverse belonging. However, this is a topic that deserves continued investigation. For further study, we suggest that interviews be carried out with nonactivist and non-urban gender-diverse individuals in both Norway and Japan. Exploring how gender variance is experienced and addressed among those who are not involved in the trans rights movement would be highly beneficial for further investigating the limitations of institutional support in each country.

\section{Notes}

1 Law 111, or the Gender Identity Disorder Special Cases Act. This law has been challenged by human rights activists on multiple grounds, including the requirement for patients to be diagnosed with gender identity disorder, to be at least 20 years old (thus disallowing children or youth), to have no children under 20 years, to be not married (thus forcing married patients to divorce), and to undergo extensive and unnecessary surgery to become sterilised (Human Rights Watch [HRW], 2019).

2 Several of the interview participants shared that they believed the certificate offered no real protection from discrimination when using public restrooms without 'passing' as one's personal gender identity, since the general public does not understand the certificate's significance and would not accept it as justification. Almost none of the participants said they used their certificate at all, aside from when attending medical clinics or changing their legal name. 


\section{2 france rose hartline and Keiichiro Ishimaru}

\section{References}

Aultman, B.L. (2018). Feeling as knowing: Trans phenomenology and epistemic justice. [Doctoral dissertation, City University of New York]. CUNY Academic Works.

Connell, R. (2007). Southern theory: The global dynamics of knowledge in social science. Allen \& Unwin.

hartline, f. (2020a). The (trans)gender equality paradox: Challenging Norway's 2016 law on gender recognition. [Doctoral dissertation]. Norwegian University of Science and Technology].

hartline, f.r. (2020b). Exploring the (cis)gender imaginary in the Nordic Region. Journal of Gender Studies, 1(23).

Human Rights Watch [HRW]. (2019). 'A really high hurdle': Japan's abusive transgender legal recognition process. [Report]. https://www.hrw.org/report/2019/03/19/ really-high-hurdle/japans-abusive-transgender-legal-recognition-process

Japanese transgender man loses appeal against enforced sterilisation. (2019, 24 January). SBS News. https://www.sbs.com.au/news/japanese-transgender-manloses-appeal-against-enforced-sterilisation

Massad, J. (2002). Re-orienting desire: The gay international and the Arab world. Public Culture, 12(2): 361-385.

McLelland, M., Suganuma, K., \& Welker, J. (Eds.). (2007). Queer voices from Japan. Lexington Books.

Probyn, E. (1996). Outside belongings. Routledge.

Robertson, J. (2017, 28 February). Japan's gender-bending history. University Wire [newspaper]. University of Michigan.

Sørlie, A. (2015). Legal gender meets reality: A sociolegal children's perspective. Nordic Journal of Human Rights, 33(4): 353-379.

Sørlie, A. (2018). The right to trans-specific healthcare in Norway: Understanding the health needs of transgender people. Medical Law Review, 27(2): 1-23.

Sprague, J. (2016). Feminist methodologies for critical researchers: Bridging differences (2nd ed.). Rowman \& Littlefield.

Stryker, S. \& Bettcher, T.M. (2016). Introduction trans/feminisms. TSQ: Transgender Studies Quarterly, 3(1-2): 5-14.

Suganuma, K. (2012). Contact moments (vol. 1). Hong Kong University Press.

Tudor, A. (2017). Dimensions of transnationalism. Feminist Review, 117: 20-40.

Van der Ros, J. (2017). The Norwegian state and transgender citizens: A complicated relationship. World Political Science, 13(1): 123-150.

Yuval-Davis, N. (2009). Identity, citizenship and contemporary, secure, gendered politics of belonging. In A. Denis, \& D. Kalekin- Fishman (Eds.), The ISA handbook in contemporary sociology: Conflict, competition, cooperation (pp. 29-41). SAGE Publications. 